\title{
Psychological Insulin Resistance (PIR) Among Type 2 Diabetes Patients at Public Health Clinics in Federal Territory of Malaysia
}

\author{
Nur Azmiah Z, a Zulkarnain AK, a Tahir A ${ }^{\mathrm{b}}$ \\ anstitute for Health Systems Research, Jalan Rumah Sakit Bangsar, 59000, Kuala Lumpur \\ bInstitute for Public Health, Jalan Rumah Sakit Bangsar, 59000, Kuala Lumpur
}

\begin{abstract}
Introduction: Insulin has been viewed as a treatment option of last resort in type 2 diabetes management. The decision to start insulin therapy is often difficult. Patients are usually reluctant to begin insulin and many cases delay the initiation of insulin therapy. The aim of this study is to determine the magnitude of insulin refusal or recognize as psychological insulin resistance (PIR) and to identify its predictors. Materials and Methods: This is a cross-sectional study and data was collected from two primary public health clinics in Kuala Lumpur and Putrajaya. The study sample consisted of 404 insulin naive patients with type 2 diabetes. A self-administered questionnaire was used to obtain demographic and clinical information. Results: Fifty-one percent of patients with type 2 diabetes were found to be unwilling to take insulin. Regression analysis revealed that females were 2.7 times more likely to resist insulin treatment compared to males and those with uncontrolled diabetes were 1.8 times more likely to resist insulin treatment compared to controlled diabetics. Patients will refuse insulin if they perceived their diabetes worsen with insulin use. After controlling for other attitudinal belief factors in the model, an increase in one unit of perceived disease severity will increase the likelihood of PIR around 2 times. Conclusion: Several misconceptions regarding insulin therapy were identified and specific education intervention is recommended for successful transition to insulin therapy.
\end{abstract}

KEYWORDS: Psychology, insulin resistance, type 2 diabetes mellitus, insulin, refusal, Malaysia INTRODUCTION

Resistance to start insulin therapy in a timely manner in type 2 diabetes has been identified as an important barrier to achieve recommended levels of glycemic control. ${ }^{1,2}$ Reluctance to initiate or intensify the insulin both in patients and physicians has been termed as 'psychological insulin resistance' or PIR. ${ }^{3}$ To address this issue a global study sponsored by Novo Nordisk called Diabetes Attitudes Wishes and Needs (DAWN) study has been conducted in 13 countries, which recruited 5000 diabetic patients and 3000 healthcare diabetes professionals. It was found that more than half of all type 2 diabetes not using insulin worry about having to start on insulin and believed that starting insulin meant they had not followed the treatment properly. ${ }^{4}$ Another landmark study was the United Kingdom Prospective Diabetes Study (UKPDS) in 1995 , which revealed that at least $50 \%$ of patients with type 2 diabetes will need insulin within 6 years of diagnosis. ${ }^{5}$ Despite the demonstrated efficacy

Corresponding author:

Nur Azmiah Zainuddin

Institute for Health Systems Research,

J alan Rumah Sakit Bangsar, 59000, Kuala Lumpur.

Telephone: +603-22971555

Fax: $+603-22971513$

E-mail: nurazmiah.z@ihsr.gov.my of insulin therapy, the initiation of insulin therapy in patients with poor glycaemic control is often delayed. ${ }^{4,6,7}$ In a recent survey of insulin-naive type 2 patients, $28 \%$ of the respondents were reported to be not willing to take insulin if it is being prescribed. Study done by Larkin et al. at an outpatient diabetes centre showed a higher prevalence of PIR (33\%). ${ }^{2}$ Study among Bangladeshi in a London hospital reported $43(20.3 \%)$ refused insulin even after repeated counseling. ${ }^{8}$

Patients express concerns about insulin based on personal experiences or information they received. PIR was found to be strongly associated with the belief that starting insulin would indicate that they had 'failed' to adequately self-manage their diabetes, fear about social stigma, perceiving insulin therapy as burdensome and too complex, worries about painful injections, the risk of hypoglycemia and anticipated weight gain. ${ }^{1,4,9}$ Understanding the characteristics of PIR is useful in designing effective intervention for starting insulin earlier in the management of type 2 diabetes. Since negative experiences or any misconception about insulin intake may influence their practices, we would like to investigate whether the factors associated with PIR from international studies also applicable in Malaysian context. Therefore, we conducted this study to measure the magnitude of PIR and to identify its predictors. 


\section{MATERIALS AND METHODS}

\section{Subjects}

This is a descriptive cross-sectional study. Data collection was carried out at two purposively selected public health clinics in Kuala Lumpur and Putrajaya for a duration of one month from April to May 2009. Sample size was calculated using Sample Size Calculator for Prevalence Studies version 1.1.01 with $95 \%$ level of confident, $40 \%$ prevalence of PIR, 5\% precision and infinite population count. $^{2,8}$ The minimum sample size required was 398 after 20\% allowance for the non-responders.

\section{Data Collection Measures}

Respondent's inclusion criteria were those diagnosed with type 2 diabetes and currently treated with an oral hypoglycemic agent (OHA), never used insulin, spoke and read both Bahasa Malaysia and English and had no visual deficits or impaired manual dexterity that would impede self-injection. ${ }^{2}$ Patients were informed about the study and gave their written consent. The study was approved by the Medical Research Ethics Committee (MREC) Malaysia and registered with the National Medical Research Registry (NMRR).

The study instrument was a self-administrated questionnaire. The data collected included age, gender, ethnicity, employment status, education level, diabetes duration and their results of random blood sugar (RBS) or fasting blood sugar (FBS) on the visiting day. Those with FBS ranging from $4.4-6.1$ $\mathrm{mmol} / \mathrm{L}$ and $\mathrm{RBS}$ ranging from $4.4-8.0 \mathrm{mmol} / \mathrm{L}$ were classified as controlled diabetics. ${ }^{10}$ Patients were asked whether they know what insulin was and how it has to be administered; whether they knew anybody ever using insulin and how they perceived of insulin benefits. The respondents were asked about their willingness to start insulin therapy if prescribed, rated from very willing to not willing. Patients were asked to rate on a five-point Likert scale ${ }^{11}$ how strongly they agreed or disagreed (1-Strongly disagree; 2-Disagree; 3-Not sure; 4-Agree; 5-Strongly agree) with eighteen attitudinal items. This measured self-perception about fifteen negative attitudes and three positive attitudes about insulin therapy. The attitudinal items were identified from three recent studies.111,12 The questionnaire was tested for content and face validity. The forward and backward translation was carried out by language expert. The questionnaire was pre-tested on 30 subjects giving reliability for attitudinal belief items as Cronbach's alpha 0.77. The eighteen attitudinal belief items were also classified into five attitudinal belief domains by conducting factor analysis.

\section{Statistical Measures}

Data was analysed using Statistical Package for Social Sciences (SPSS) version 15.0 computer software. Means and standard deviations (SDs) were reported for continuous variables and proportions for categorical variables. We used chi-square test to examine differences in proportion between those who accepted and those who resisted insulin therapy. Bivariate and multivariate logistic regression analysis using enter method was carried out to assess the relationship among demographic data, attitudinal belief domains and willingness to start insulin therapy. $\mathrm{P}$ value of less than 0.05 was considered to be statistically significant.

\section{RESULTS}

A total of 420 respondents were approached by the researcher and 404 agreed to participate giving a respond rate of $96.2 \%$. The respondents' ages were between 25 and 83 years. The mean age was 54.5 (34.9, 74.1) years. The median for the duration of diabetes was $4(2,9)$ years. Majority of the patients were male $(57.2 \%)$, Malay $(71.0 \%)$, still working $(55.5 \%)$ and had at least a secondary education $(85.4 \%)$.

The proportion of PIR was $50.7 \%$ as shown in Figure 1. PIR were higher among female compared to male, those uncontrolled diabetes group compared to control and those who perceived insulin therapy made no difference to their condition compared to those who perceived insulin therapy as benefitting to them (Table I).

\section{Willingness towards Insulin Therapy}

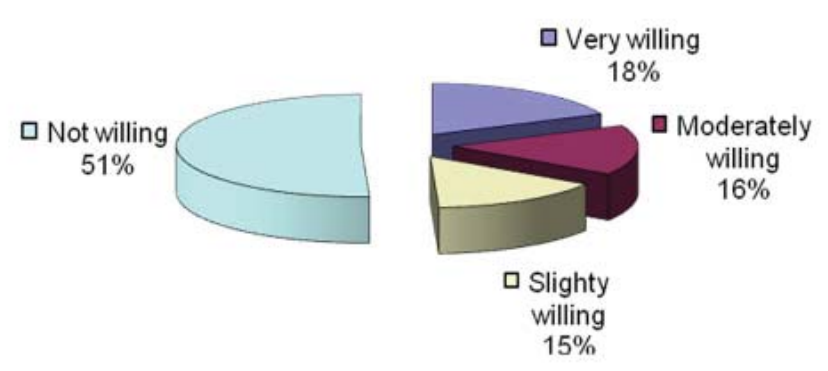

Figure 1. Willingness to initiate insulin therapy ( $N=404$; $42.8 \%$ female, $71 \%$ Malay 
Table I. Patients' Characteristics and Willingness to Insulin Therapy ( $N=404)$

\begin{tabular}{|c|c|c|c|c|}
\hline & & Willingness & & \\
\hline Characteristics & $\mathrm{n}(\%)$ & Willing & Resistance & $p$ \\
\hline Overall & $404(100.0)$ & $199(49.3)$ & $205(50.7)$ & \\
\hline Age & & & & \\
\hline$<=40$ & $30(7.4)$ & $17(56.7)$ & $13(43.3)$ & \\
\hline $41-60$ & $271(67.1)$ & $128(47.2)$ & $143(52.8)$ & 0.468 \\
\hline $61+$ & $103(25.5)$ & $54(52.4)$ & $49(47.6)$ & \\
\hline Gender & & & & \\
\hline Male & $231(57.2)$ & $131(56.7)$ & $100(43.3)$ & $<0.001$ \\
\hline Female & $173(42.8)$ & $68(39.3)$ & $105(60.7)$ & \\
\hline Ethnic & & & & \\
\hline Malay & $287(71.0)$ & $135(47.0)$ & $152(53.0)$ & \\
\hline Chinese & $57(14.1)$ & $36(63.2)$ & $21(36.8)$ & 0.159 \\
\hline Indian & $50(12.4)$ & $23(46.0)$ & $27(54.0)$ & \\
\hline Others & $10(2.5)$ & $5(50.5)$ & $5(50.0)$ & \\
\hline Working Status & & & & \\
\hline Not working & $151(37.4)$ & $71(47.0)$ & $80(53.0)$ & 0.946 \\
\hline Working & $96(23.8)$ & $56(58.3)$ & $40(41.7)$ & \\
\hline Education Level & & & & \\
\hline $\begin{array}{l}\text { Primary / Not } \\
\text { schooling }\end{array}$ & $59(14.6)$ & $24(40.7)$ & $35(59.3)$ & \\
\hline Secondary & $210(52.0)$ & $104(49.5)$ & $106(50.5)$ & 0.310 \\
\hline Tertiary & $135(33.4)$ & $71(52.6)$ & $64(47.4)$ & \\
\hline Duration Of Diabet & & & & \\
\hline$<5$ & $204(50.5)$ & $102(50.0)$ & $102(50.0)$ & \\
\hline $5-10$ & $145(35.9)$ & $73(50.3)$ & $72(49.7)$ & 0.656 \\
\hline$>10$ & $53(13.1)$ & $23(43.4)$ & $30(56.6)$ & \\
\hline Diabetes status & & & & \\
\hline Un-control & $257(63.6)$ & $116(45.1)$ & $141(54.9)$ & 0.022 \\
\hline Control & $112(27.7)$ & $64(57.1)$ & $48(42.9)$ & \\
\hline How do you perceiv & sulin benefit & & & \\
\hline Benefitting & $214(81.7)$ & $115(53.7)$ & $99(46.3)$ & \\
\hline No different & $32(12.2)$ & $6(18.8)$ & $26(81.3)$ & $<0.001$ \\
\hline Hurting & $16(6.1)$ & $4(25.0)$ & $12(75.0)$ & \\
\hline
\end{tabular}


The most frequently expressed negative attitudes were personal failure $(59.2 \%)$, injecting is embarrassing (55.9\%) and injecting is painful (50.7\%). When resistance and willing subjects were compared, they differed significantly on all items except for thinking that regular blood sugar check is painful and insulin has to be taken continuously. Respondent who were resistance had a higher percentage of agreement on all negatively stated items and lower percentages of agreement for all three positive attitudinal items number 13 , 15 and 16 as in Table II.

Table II. Attitudinal beliefs about insulin therapy, resistance versus willing subjects.

\begin{tabular}{|c|c|c|c|c|c|c|c|c|}
\hline \multicolumn{2}{|c|}{ Barrier/attitude } & \multicolumn{4}{|c|}{ Willingness to take insulin } & \multicolumn{2}{|c|}{ Total $(\mathrm{N}=404)$} & \multirow[t]{3}{*}{$p$ value } \\
\hline & & \multicolumn{2}{|c|}{ Resistance(n=205) } & \multicolumn{2}{|c|}{ Willing $(n=199)$} & & & \\
\hline & & $\mathrm{n}$ & $\%$ & $\mathrm{n}$ & $\%$ & $\mathrm{n}$ & $\%$ & \\
\hline 1 & Personal failure & 133 & 64.9 & 106 & 53.3 & 239 & 59.2 & 0.006 \\
\hline 2 & Injecting is embarrassing & 133 & 64.9 & 93 & 46.7 & 226 & 55.9 & $<0.001$ \\
\hline 3 & Injecting insulin is painful & 124 & 60.5 & 81 & 40.7 & 205 & 50.7 & $<0.001$ \\
\hline 4 & Fear of problematic hypoglycemia & 112 & 54.6 & 81 & 40.7 & 193 & 47.8 & $<0.001$ \\
\hline 5 & Lack of fairness & 104 & 50.7 & 72 & 36.2 & 176 & 43.6 & $<0.001$ \\
\hline 6 & Restrictiveness & 102 & 49.8 & 62 & 31.2 & 164 & 40.6 & $<0.001$ \\
\hline 7 & Insulin has to be taken continuously & 100 & 48.8 & 88 & 44.2 & 188 & 46.5 & 0.219 \\
\hline 8 & Can't pay close attention to diet. & 92 & 44.9 & 65 & 32.7 & 157 & 38.9 & 0.033 \\
\hline 9 & $\begin{array}{l}\text { Don't have enough time for regular } \\
\text { doses of insulin }\end{array}$ & 87 & 42.4 & 50 & 25.1 & 137 & 33.9 & $<0.001$ \\
\hline 10 & I feel like drug addicts & 77 & 37.6 & 43 & 21.6 & 120 & 29.7 & $<0.001$ \\
\hline 11 & Low self efficacy & 75 & 36.6 & 70 & 35.2 & 145 & 35.9 & 0.042 \\
\hline 12 & Disease severity & 72 & 35.1 & 54 & 27.1 & 126 & 31.2 & 0.045 \\
\hline 13 & People with insulin feel better & 64 & 31.2 & 101 & 50.8 & 165 & 40.8 & $<0.001$ \\
\hline 14 & Regular blood-sugar checks are painful. & 60 & 29.3 & 49 & 24.6 & 109 & 27 & 0.543 \\
\hline 15 & Insulin can prevents complications & 49 & 23.9 & 87 & 43.7 & 136 & 33.7 & $<0.001$ \\
\hline 16 & Insulin works better than pills & 46 & 22.4 & 84 & 42.2 & 130 & 32.2 & $<0.001$ \\
\hline 17 & Can cause other problem like blindness & 31 & 15.1 & 12 & 6.0 & 43 & 10.6 & $<0.001$ \\
\hline 18 & Causes weight gain & 20 & 9.8 & 10 & 5.0 & 30 & 7.4 & 0.015 \\
\hline
\end{tabular}

Data are the number and percentages of subjects who agree (strongly and agree) with each barrier/attitude. $P$ value compare differences between resistance and willing subjects

Further analysis using attitudinal belief domains showed that most patients reported a predominantly positive insulin related outcome expectation. Personal failure was the most common barrier to insulin therapy, followed by lack of self-empowerment, perceived disease severity and finally fears of injection (Figure 2 ). 


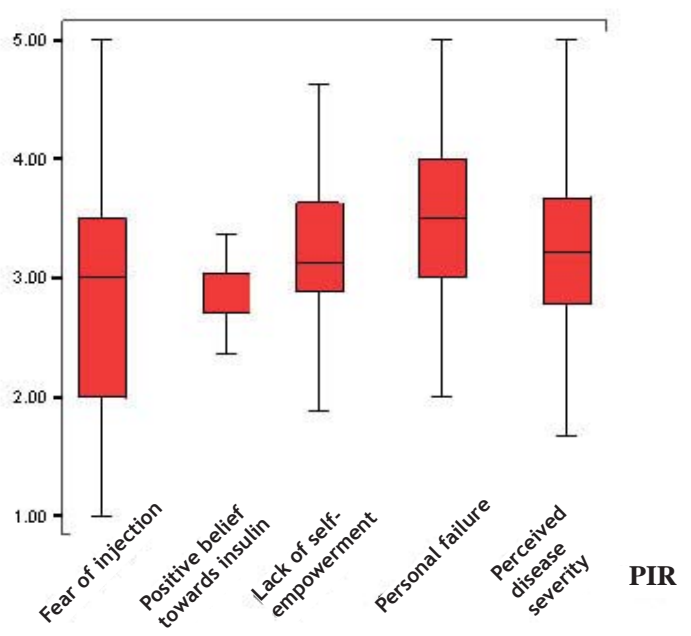

Figure 2. PIR score for different domains of attitudinal belief

In univariate model, sex, ethnicity, diabetic status and all five domains of perception on insulin were significant predictors for PIR. Multivariable analysis for PIR showed that sex, diabetic status and three domains of perception on insulin were significant predictors for PIR. After controlling for other variables, female were 2.7 times more likely to resist insulin treatment compared to male $(O R=2.71$; $\mathrm{p}<0.001$ ) while those who were uncontrolled diabetics were 1.8 times more likely to resist insulin treatment compared to controlled diabetic patients $(\mathrm{OR}=1.86$; $p=0.025$ ). Similarly, after controlling for other variables in the model, an increase in one unit of positive belief towards insulin will decrease the likelihood of PIR more than 3 times $(O R=0.322 ; p<0.001)$. Perceived disease severity and personal failure were other predictors for PIR. After controlling for other attitudinal belief factors in the model, an increase in one unit of perceived disease severity will increase the likelihood of PIR around 2 times (OR=2.124; $p=0.015)$ while an increase in one unit of personal failure will increase the likelihood of PIR around 1.7 times $(O R=1.652 ; p<0.001)$. The remaining two predictors did not have significant odd ratios. $\mathrm{R}^{2}$ value was 0.344 (Nagelkerke) which showed a considerably good model.

\section{DISCUSSION}

This study found that more than half of diabetic patients in public health clinic will refuse insulin when prescribed. Female and patients with uncontrolled diabetes were more likely to refuse. Despite the positive expectation towards insulin, patients who perceived that their diabetes worsened and blamed themselves for needing insulin were more likely to reject insulin therapy.

The prevalence of PIR (50.7\%) was higher than previous studies among western communities. ${ }^{1,2}$ Furthermore both studies reported that the true prevalence of PIR was significantly higher probably because their study samples were among relatively motivated 1 and good glucose control patients. ${ }^{2}$ However, a study on Bangladeshi patients with poorly controlled type 2 diabetes in East London showed a comparable result whereby $42.5 \%$ refused insulin when it was first recommended. ${ }^{8}$ The differences in magnitude of PIR was emphasised in the DAWN study conducted in 13 countries in Asia, Europe and North America, which showed that belief about insulin was related to culture and health care systems of different countries. ${ }^{4}$

The negative attitude that predicts patients to refuse insulin were perceived disease severity and personal failure. For many patients, insulin therapy signified that their diabetes was suddenly more serious and more dangerous. ${ }^{1,2,8,13}$ Similarly with Hunt et al. reported that many patients were concerned that insulin therapy may cause further health problems. ${ }^{14}$ In some cases, such beliefs may be at least partially correct (e.g. a slightly increased hypoglycemia risk and weight gain), while in other cases (e.g. taking insulin can cause blindness), they may be quite wrong. Not surprisingly, if people are convinced that insulin will worsen their health, they may be very resistant to begin insulin therapy. ${ }^{9,15,16}$

Most patients expressed several reasons for avoiding insulin, rather than just one. The DAWN study also found that $58 \%$ patients with diabetes saw the need for insulin as an indication that they had failed to manage their diabetes properly, or it was a punishment. ${ }^{4}$ In other words, insulin is viewed as a well-deserved punishment for one's negligence in some other areas of diabetes self-care. The negative attitude that most strongly distinguished willing to unwilling subjects was the belief that starting insulin would indicate that they had 'failed' proper diabetes self-management. ${ }^{1}$ Patients may associate insulin therapy with the sense of personal failure due to common physician practice, where the possibility of insulin therapy may be used as a threat to motivate better patient cooperation. ${ }^{3}$

These results lead to several implications for clinical practice. PIR is typically presented as a set of beliefs about the meaning of insulin therapy. Firstly, patients may be unable to overcome their insulin therapy reluctance until their personal concerns were recognised and addressed. Secondly, patients need to be made to understand that the failure of therapy is not their fault but is due to the progressive nature of the disease, thus the use of insulin is both appropriate and necessary in many patients with type 2 diabetes. Thirdly, the benefit of insulin therapy in terms of increased vitality and reduction in risk of complications must be emphasised. Using 'expert patient' who had positive experiences of insulin commencement may also increase the likelihood of patients commencing insulin. 9,16,17 Further studies focusing on insulin as a positive addition to improve glycemic control instead of the medication of last resort are recommended. 
The limitation of our study included the barriers to insulin therapy were based on a hypothetical suggestion, not actual behavior and patients were not followed longitudinally to measure PIR at the time of insulin initiation. The result showed an association and not causal relationship. The pool of attitudinal items was limited and there are other important contributors to PIR that were not assessed, for example, fatalistic lines as the test from God, ${ }^{8}$ non-compliance, use of alternative medicine, financial constraints and lack of continuity of care. ${ }^{6}$ Another important contributor to PIR which is not measured is the provider barriers. ${ }^{4,6,7}$

\section{CONCLUSION}

When patients are reluctant to accept insulin, PIR should be explored. Providers might begin by questioning patients about their knowledge of insulin therapy and their underlying beliefs. Exploring why each patient is unwilling to take insulin can help address his or her specific fear or misperception and facilitate a smoother transition to it. Insulin should now be viewed as a valuable therapeutic tool for early intervention that allows patients to attain and maintain the target level of blood glucose. While there are many ways to implement insulin therapies, the one that the patients understand and agree to is likely to be the most effective approach.

\section{CONFLICT OF INTEREST}

There is no commercial association that might create a conflict of interest in connection with this submitted manuscript. All authors are affiliated with the Ministry of Health Malaysia and receive no financial benefit from the publication of this study.

\section{Acknowledgements}

We thank the Director-General of Health Malaysia for permission to publish this paper. We also wish to express our appreciations to all participants for their kind support.

\section{REFERENCES}

1. Polonsky WH, Fisher L, Guzman S, VillaCaballero L, Edelman SV.

Psychological Insulin Resistance in Patients with Type 2 Diabetes: The scope of the problem. Diabetes Care 2005; 28(10):2543-2545

2. Larkin ME, Capasso VA, Chen CL, et al. Mea suring Psychological Insulin Resistance: Bar riers to Insulin Use. The Diabetes Educator 2008; 34(3):511-517

3. Polonsky WH, Jackson RA. What's So Tough About Taking Insulin? Addressing the Problem of Psychological Insulin Resistance in Type 2
Diabetes. Clinical Diabetes 2004; 22(3):147150

4. Peyrot M, Rubin RR, Lauritzen T, et al. Resis tance to Insulin Therapy Among Patients and Providers Results of the cross-national Dia betes Attitudes, Wishes, and Needs (DAWN) study. Diabetes Care 2005; 28(11):2673-2679

5. Turner RC, Holman RR. Lesson from UK Prospective Diabetes Study. Diabetes Res Clin Pract 1995; S151-S157

6. Haque M, Emerson SH, Dennison CR, et al. Barriers to initiating insulin therapy in $\mathrm{pa}$ tients with type 2 diabetes mellitus in pub lic-sector primary health care centres in Cape Town. South African Medical Journal 2005; 95(10):798-802

7. Hayes RP, Fitzgerald JT, Jacober SJ. Primary care physician belief about insulin initiation in patients with type 2 diabetes. Internation al Journal of Clinical Practice 2008; 62(6):860-868

8. Khan H, Lasker SS, Chowdhury TA. Preva lence and reasons for insulin refusal in Bangladeshi patients with poorly controlled Type 2 diabetes in East London. Diabetic Medicine 2008; 25(9):1108-1111

9. Meece J. Dispelling Myths and Removing Bar riers About Insulin in Type 2 Diabetes. The Diabetes Educator 2006; 9S-18S

10. Malaysia, Ministry of Health. Clinical Prac tice Guideline for treatment of Type 2 Dia betes. 2009

11. Snoek FJ, Skovlund SE, Pouwer F. Develop ment and validation of the insulin treat ment appraisal scale (ITAS) in patients with type 2 diabetes. Health and Quality of Life Outcome 2007; 5(69):1-7

12. Petrak F, Stridde E, Leverkus F, et al. Devel opment and Validation of a New Measure to Evaluate Psychological Resistance to Insulin Treatment. Diabetes Care 2007; 30(9):21992204

13. Polonsky WH, Fisher L, Dowe S, Edelman S. Why Do Patients Resist Insulin Therapy? (Ab stract). Diabetes 2003; 52:A417

14. Hunt LM, Valenzuela MA, Pugh JA. NIDDM patients' fears and hopes about insulin therapy: the basis of patient reluctance. Diabetes Care 1997; 20(3):292-298

15. Funnell MM. Overcoming Barriers to the Initiation of Insulin Therapy. Clinical Diabe tes. 2007; 25(1):36-38.

16. Peragallo-Dittko V. Removing Barriers to In sulin Therapy. The Diabetes Educator. 2007; 33(Supplement 3):60S-65S.

17. Gavin JR, Peragallo-Dittko V, Rodgers PT. A New Look at Established Therapies. The Diabetes Educator. May-June 2010; 36(Supplement 2):26S-38S. 